\title{
ANALYSIS OF BUS PERFORMANCE ON THE RISK OF TRAFFIC ACCIDENTS IN EAST JAVA-INDONESIA
}

\author{
Aji Suraji \\ Department of Civil Engineering \\ University of Widyagama Malang \\ $35 \mathrm{Jl}$. Borobudur, Mojolangu, Kec. Lowokwaru, Kota Malang, Jawa East Java-Indonesia \\ Department of Civil Engineering ${ }^{l}$ \\ aji172.gh@gmail.com,ajisuraji@widyagama.ac.id
}

Ludfi Djakfar

Department of Civil Engineering ${ }^{l}$

Ldjakfar@ub.ac.id

Achmad Wicaksono

Department of Civil Engineering ${ }^{I}$

wicaksono68@ub.ac.id

${ }^{1}$ Brawijaya University

$167 \mathrm{Jl}$. Mayjend Haryono, Malang, Indonesia, 65145

\begin{abstract}
Bus transportation performance must be able to demonstrate safety performance capabilities, one of which is the condition of the vehicle. Therefore, to achieve bus vehicles' safety performance, research must be carried out to determine the causes of accidents. This study aims to determine the causes of accidents related to vehicle conditions. Some of the variables that are observed include brake, wheel, equipment, stability, and worthiness. The data collection method used is to collect secondary data on the incidence of accidents from each Resort Police Office in each district traversed by the intercity public bus route. The roads traversed by the public bus transportation routes between the cities that are the object of the study include Sidoarjo Regency, Pasuruan Regency, Probolinggo Regency, Mojokerto Regency, Madiun Regency, and Ngawi Regency. The analytical method to obtain mathematical modeling is to use Principal Component Analysis (PCA). The results show that five factors analyzed, four main actors, cause intercity bus accidents, namely brakes, wheels, stability, and worthiness. The four factors are interrelated with each other, where these factors support each other and trigger accidents and obtained a mathematical model of the factors causing the accident which can be explained by two mathematical equations, namely $P C_{1}=0.61 X_{1}+0.70 X_{2}+0.46 X_{3}+0.63 X_{4}+0.72 X_{5}$ and $P C_{2}=-0.47 X_{1}-0.17 X_{2}+0.76 X_{3}-0.26 X_{4}+0.31 X_{5}$. The study results also illustrate that accidents caused by an inappropriate wheel are always followed by a breakdown of the braking system that is not functioning properly, and the wheel system consisting of wheel and brake conditions will be a problem triggering the accident.

Keywords: bus performance, risk, traffic, accident, transportation, principal component analysis, East Java.
\end{abstract}

DOI: $10.21303 / 2461-4262.2021 .001820$

\section{Introduction}

In general, inter-city bus public transport in Indonesia still needs to be improved, both about direct service to bus passengers and aspects of road traffic safety. It can be seen from bus users' complaints who feel that there are still many unsatisfactory things for users of public transport buses between cities. Also, the frequent accidents involving buses indicate that Indonesia's intercity bus safety management system is still lacking. The issue of transportation safety issues is also the reason for the condition of road transportation. There are still many aspects that need to be addressed $[1,2]$.

In the safety of inter-city public bus transportation in Indonesia, the National Transportation Safety Committee (KNKT, 2016) has investigated every incident of public bus accidents that fall into serious accidents where the number of people who died reached eight or more in one incident. Data compiled by the National Transportation Safety Committee (KNKT), from 2009 to 2019, there were around 25 fatal accidents involving buses. According to the KNKT, the cause of accidents and the behavior of unskilled drivers are also due to the condition of the vehicle that is not roadworthy. The negligence of the vehicle condition can include various components of the vehicle. 
The main problem in the bus fleet is related to vehicle components that are not functioning optimally. The malfunction of the bus vehicle components can be related to aspects of vehicle maintenance management and the result of factors beyond control that cannot be avoided. Some of the main components include brakes, wheels, equipment, and other factors.

To reduce the risk of accidents, it is necessary to identify the factors that cause accidents from the vehicle aspect in more depth so that solving the problem of intercity bus accidents can be adequately resolved. For this reason, this study aims to identify the incidence of accidents involving inter-city buses and formulate the factors that cause accidents and make mathematical modeling.

\section{Bus safety performance}

Bus safety performance is an assessment of the bus worthiness condition related to the safety and ability of bus operational services and the level of risk of accidents so that the vehicle can be avoided from accidents. Therefore, observing the components which are significantly related to the level of accident risk is very important. Several components that are important about the level of accident risk include the condition of the Brake, Wheel, Equipment, Stability, and Worthiness. Driver simulations have also been carried out [3], which aims to determine the driver's performance and the response to various terrain and vehicle conditions during the simulation.

Brake and wheel is a component that plays a role in controlling the vehicle's speed. If the brake condition is in good condition, the vehicle can be adequately controlled by the driver, but if the brake condition is not good, it will increase the risk of accidents. Meanwhile, equipment is a part that supports better vehicle control operations. Stability and worthiness are components that integrate the functions of the components that affect vehicle performance. Stability is related to the ability to control the vehicle due to the load driven by the driver. Meanwhile, worthiness is more about the reasonableness of the vehicle's condition or the vehicle's worthiness to operate on the highway. Therefore, some of these components are very important for realizing bus performance to realize a safe bus [4].

\section{Accidents risk of bus}

Components of the bus fleet that do not comply with safety standards pose a risk of accidents. The guidelines issued by the Ministry of Transportation, where every bus fleet that will operate must meet predetermined safety standards [The Regulation of Transportation Minister, No. KM 35/2003]. Failures that can cause an accident risk often occur due to malfunctioning of vehicle components, such as improper braking processes, poor tire conditions [5]. Several studies that have been conducted by previous researchers have shown that vehicle factors that do not comply with safety standards can pose a risk of accidents. Conceptually, the incidence of accidents is interrelated between one cause and another, difficult to separate. Some of the combined factors can be a human, vehicle, road, and environmental errors [6, 7]. The braking system and vehicle wheels are often the main factors that can cause bus accidents. Together, these two components can affect the failure to stop the vehicle, where the vehicle cannot be controlled due to the braking system that cannot function properly [8].

\section{Methods}

Accident data involving buses are secondary data taken from the Police in 6 regions in East Java, namely Sidoarjo Regency, Mojokerto Regency, Pasuruan Regency, Probolinggo Regency, Madiun Regency, and Ngawi Regency. The pick-up location in these six areas is that these areas are crossed by intercity bus transportation routes on the national primary arterial line and have a high number of accidents involving buses.

The chronology of accidents recorded by the Police in the accident report book is compiled by observation and data sorting. The number of victims and the factors causing the accidents are examined to be sorted into variable categories formulated that lead to bus performance. There are five variables related to bus performance, namely: Brake, Wheel, Equipment, Stability, and Worthiness, respectively, given the symbols $X 1, X 2, X 3, X 4$, and $X 5$. The risk of accidents caused by intercity bus vehicles' condition is measured based on these five variables. Furthermore, accident data based on these variables are recapitulated and tabulated for use in the data processing. 
Each variable's conditions are classified into two conditions, namely good performance conditions with a value code of 1 and bad performance conditions with a value code 2 . This coding method is intended to prepare data so that it is easy to process statistically. A more detailed description of each variable can be seen in Table 1.

Table 1

Variable description of inter-city bus performance

\begin{tabular}{|c|c|c|c|c|}
\hline Symbol & Variables & Condition & Coding data & Description \\
\hline \multirow[t]{2}{*}{$X 1$} & Brake & Good brake & 1 & Good and functioning brakes include Canvas, springs, etc. \\
\hline & & Malfunctions brake & 2 & Brakes do not function \\
\hline \multirow[t]{2}{*}{$X 2$} & Wheel & Good wheel & 1 & Good wheels, including alloy wheels and tires \\
\hline & & Faulty wheel & 2 & The wheels are ugly/broken, and the tires have no grooves \\
\hline \multirow[t]{2}{*}{$X 3$} & Equipment & Good equipment & 1 & there are fixtures including lamps, send \\
\hline & & Not function equipment & 2 & No equipment or functionality \\
\hline \multirow[t]{2}{*}{$X 4$} & Stability & Stable & 1 & Vehicle stable \\
\hline & & Overload & 2 & Vehicles are not stable due to overload and unstable chassis conditions \\
\hline \multirow[t]{2}{*}{$X 5$} & Worthiness & Good worthiness & 1 & Vehicle is worth the way \\
\hline & & Not worthiness & 2 & Vehicles are not worth the way \\
\hline
\end{tabular}

Principal Component Analysis (PCA) is a statistical analysis tool used to analyze the main factors that cause intercity bus accidents. The working principle of PCA is to use a data structure approach with analysis to identify the main factors that cause it. The first step in statistical analysis to determine general conditions is to perform descriptive statistical analysis. The next step is to carry out statistical analysis using the PCA method to determine the factors influencing accidents. The PCA analysis results are in the form of mathematical modeling in the form of polynomial equations. The resulting modeling provides an indicator of influencing factors by looking at each variable's dimensions after PCA extraction. Statistical analysis is also continued by looking at the indicators of the positive and cumulative total variants. The general equation for mathematical modeling using PCA memory is as shown in Equation 1,

$$
P C=a X_{1}+b X_{2}+c X_{3}+d X_{4}+\ldots+n X_{n}
$$

The general modeling equation shows that each variable will explain the factors that influence the accident. The coefficient on each variable shows the level of the variable's contribution strength, where the coefficient value can be in the form of positive or genetic numbers.

\section{Result}

\section{1. Data and analysis}

Data on traffic accidents involving inter-city buses in the province of East Java have been compiled from 6 districts, which are traffic corridors passed by intercity buses. Areas that are the data collection object include Sidoarjo Regency, Mojokerto Regency, Pasuruan Regency, Probolinggo Regency, Madiun Regency, and Ngawi Regency. Accident incidents that have been collected are accident data spanning from 2014 to 2018.

Each accident has recorded the accident magnitude's main parameters, including the number of accidents, the number of dead victims, the number of seriously injured victims, and the number of minor injured victims. The recap of accidents in each region is shown in Table 2. From this table, it can be explained that the number of accidents that have been collected is 176 accidents spread across six districts. The recap results showed that the accident resulted in 96 people dying, 284 seriously injured, and 77 minor injuries. 
Table 2

Accident severity of intercity bus in arterial roads

\begin{tabular}{cccccc}
\hline No. & Regency & No. of accidents & Dead (person) & Heavy injuries (person) & Light injuries (person) \\
\hline 1 & Sidoarjo Regency & 20 & 15 & 55 & 0 \\
2 & Mojokerto Regency & 12 & 7 & 0 & 8 \\
3 & Pasuruan Regency & 37 & 12 & 13 & 35 \\
4 & Probolinggo Regency & 15 & 8 & 26 & 2 \\
5 & Madiun Regency & 19 & 13 & 12 & 5 \\
6 & Ngawi Regency & 73 & 41 & 178 & 284 \\
\end{tabular}

Source: Police Department of Republic Indonesia 2019

Accident data obtained from the six regions are then compiled by identifying the main factors causing the accident. The causes of accidents in this study are focused on the condition of the vehicle or bus performance. Thus, the variables that cause accidents are derived from those related to bus performance. It has been done the selection of variables that cause accidents and obtained five variables, namely: Brake, Wheel, Equipment, Stability, and Worthiness.

In each accident, the factors that cause accidents have been identified, and these factors will be the basis for analyzing the effect of bus performance on the risk of traffic accidents. As a general illustration, the causes of accidents have been recapitulated based on each area, as shown in Table 3. The recap results for the six regions based on the accident-causing variables are 18 events due to brake failure, nine events due to wheel conditions, ten due to lack of vehicle equipment, five events due to poor vehicle stability, and seven events due to very low worthiness. The results of the identification of the causes of accidents also identified factors that were not due to the performance aspect of the bus vehicle being included in the 'Others' category, which included the driver, road and environment factors, where the number of incidents which were 'other' factors was 138.

Table 3

The main causative factor of intercity bus accidents based on police department report

\begin{tabular}{ccccccccc}
\hline \multirow{2}{*}{ No. } & \multirow{2}{*}{ Regency } & No. of & \multicolumn{5}{c}{ The main factor of accidents } \\
\cline { 4 - 9 } & & accidents & Brake & Wheel & Equipment & Stability & Worthiness & Others \\
\hline 1 & Sidoarjo Regency & 20 & 3 & 0 & 1 & 0 & 0 & 16 \\
2 & Mojokerto Regency & 12 & 1 & 0 & 0 & 0 & 1 & 10 \\
3 & Pasuruan Regency & 37 & 2 & 1 & 2 & 1 & 1 & 30 \\
4 & Probolinggo Regency & 15 & 2 & 0 & 0 & 0 & 0 & 13 \\
5 & Madiun Regency & 19 & 3 & 3 & 2 & 1 & 3 & 5 \\
6 & Ngawi Regency & 73 & 7 & 5 & 5 & 3 & 4 & 7 \\
& Total & 176 & 18 & 9 & 10 & 5 & 138
\end{tabular}

From Table 3 it can be explained that from the total number of incidents in the 6 study areas, there were 176 accidents, so the largest number of incidents was dominated by the Brake and Equipment factor where the incidents had more than 10 incidents. This shows that at the initial stage of the data recap, the two factors indicated a greater influence than the other factors. It should be noted that this data recap stage still does not use statistical analysis as a data processing tool. Therefore, the results of more in-depth analysis can be seen at the statistical analysis stage using the PCA method.

\section{2. Mathematical modeling of accidents}

The statistical analysis begins with making a descriptive analysis of the variables that cause accidents. In the descriptive analysis, each category's frequency is identified, both those that have a positive contribution to safety and those that are malfunctioning of each variable. The value of the 
descriptive analysis results is in the form of a percentage of each existing category, and the results of the descriptive analysis as referred to in Table 4. From this table, it can be explained that the malfunction of each variable varies where the greatest value is on brake failure, which is $10.2 \%$, meanwhile variable wheel, equipment, and worthiness have a value between $4 \%$ to $5 \%$ where this value is included at the intermediate level. At the same time, the smallest percentage value is found in the stability variable with a value of $2.8 \%$.

It shows that the variable brake has a large weight contributing to accidents, followed by the other three variables, namely variable wheel, equipment, and worthiness. Failure of the braking system when the bus travels at high speed will provide a greater chance of an accident risk. This study's results are in line with research conducted, which states that the braking system has a significant contribution to accidents [7].

Table 4

Descriptive analysis of vehicle variable

\begin{tabular}{cccc}
\hline Variable & Category & Frequency & Percentage (\%) \\
\hline Brake & Good brake & 158 & 89.8 \\
& Malfunction brake & 18 & 10.2 \\
& Total & 176 & 100.0 \\
Wheel & Good wheel & 167 & 94.9 \\
& Faulty wheel & 9 & 5.1 \\
& Total & 176 & 100.0 \\
Equipment & Good equipment & 166 & 94.3 \\
& Not function equipment & 10 & 5.7 \\
Stability & Total & 176 & 100.0 \\
& Stable & 171 & 97.2 \\
& Unstable & 5 & 2.8 \\
Worthiness & Total & 176 & 100.0 \\
& Good worthiness & 169 & 96.0
\end{tabular}

Table 4 shown the mathematical modeling consists of the factors that influence accidents. The PCA method is used to extract dimensions. The extraction process is intended to determine the coefficient value of each variable in mathematical modeling. There are five dimensions to extract each variable as referred to in Table 5. Each dimension produces eigenvalues, total variants, and cumulative total variants. Each variable's eigenvalue is seen from its value with a cut-off value of 1 , which is significant if the eigenvalue is more than 1. Based on PCA extraction PCA, the dimensions with an eigenvalue of more than 1 are dimension one and dimension 2 with values of 2.01 and 1.01, respectively.

Table 5

PCA extraction of the variables

\begin{tabular}{cccccc}
\hline Variable (symbol) & \multicolumn{5}{c}{ Dimension } \\
\cline { 2 - 6 } & $\mathbf{1}$ & $\mathbf{2}$ & $\mathbf{3}$ & $\mathbf{4}$ & $\mathbf{5}$ \\
\hline Brake $\left(X_{1}\right)$ & 0.61 & -0.47 & -0.36 & -0.46 & 0.21 \\
Wheel $\left(X_{2}\right)$ & 0.70 & -0.17 & -0.35 & 0.47 & -0.34 \\
Equipment $\left(X_{3}\right)$ & 0.46 & 0.76 & -0.14 & -0.34 & -0.24 \\
Stability $\left(X_{4}\right)$ & 0.63 & -0.26 & 0.67 & -0.14 & -0.24 \\
Worthiness $\left(X_{5}\right)$ & 0.72 & 0.31 & 0.15 & 0.27 & 0.52 \\
Eigen value & 2.01 & 1.01 & 0.75 & 0.66 & 0.56 \\
Total variant $(\%)$ & 40.22 & 20.19 & 15.12 & 13.21 & 11.27 \\
Cumulative of total variant $(\%)$ & 40.22 & 60.41 & 75.53 & 88.73 & 100.00
\end{tabular}


Modeling with the PCA method is seen from the Eigen Value on each dimension whose value is more than 1 . While the cumulative Eigen value limit is considered a fairly representative modeling if the value is more than $60 \%$. Table 5 shown PCA results have two dimensions with eigenvalues of more than 1 , namely the first and second dimensions with the cumulative total variance that can be explained is $60.41 \%$. These two dimensions are sufficient to replace the extraction of the five variables in the vehicle factor. The equations generated from both dimensions are shown in equation (2) and equation (3):

$$
\begin{gathered}
P C_{1}=0.61 X_{1}+0.70 X_{2}+0.46 X_{3}+0.63 X_{4}+0.72 X_{5} \\
P C_{2}=-0.47 X_{1}-0.17 X_{2}+0.76 X_{3}-0.26 X_{4}+0.31 X_{5} .
\end{gathered}
$$

In the first dimension $\left(P C_{1}\right)$, the large coefficient is on the brake $\left(X_{1}\right)$, wheel $\left(X_{2}\right)$, stability $\left(X_{4}\right)$, and worthiness $\left(X_{5}\right)$, and all four are positive. This first dimension explains the existence of a stronger relationship between the four variables. This dimension explains that the cause of accidents is from vehicle factors, $40.22 \%$ explained by brakes, wheels, stability, and worthiness. What is interesting is that the equipment variable has the lowest coefficient among other variables. It shows that the equipment variable does not make a significant contribution to accidents. So the findings obtained from the modeling of the factors that affect city buses' traffic can be explained based on these two equations. This study has similarities in terms of the methods used, both of which use the PCA method to analyze accidents [9]. However, there are differences in the things that are the object of research. The bus accident model was developed to make accident model predictions with different determinations of accident variables [10]. The focus of the research carried out was driven by the factors that caused the accident, besides the bus condition factors needed special attention [11].

The results of this study are almost the same as the results of research using a motorbike object where the results of this study state that the equipment variable has no significant effect on accidents [12]. The difference in approach and object of this research with research is identical, even though it is the same as modeling the factors that affect accidents and the results are almost the same, of course there is something undesirable that needs to be considered as a note [13].

The second dimension $\left(P C_{2}\right)$ coefficient is large only in the fixture $\left(X_{3}\right)$. This dimension explains that the cause of accidents is from vehicle factors, $20.19 \%$ of which are explained by the equipment. This extraction provides several conclusions that vehicle problems are near related to brake conditions, equipment, stability, and worthiness in many locations. The data of this study indicate a tendency of vehicle conditions with brake and stability problems and a lack of equipment and worthiness [14].

The results of this study provide a more detailed description of the causes of accidents as conducted by [14]. The two studies have a slight difference. Namely, this study focuses more on aspects of the bus vehicle's condition, while the research conducted by [6] emphasizes the campaign on bus safety performance. Research conducted by [8] has also developed the component aspects of the vehicle that cause accidents and the speed factor when the vehicle is driving at high speed.

\section{Discussion of analysis results}

The analysis results by getting two dimensions in the modeling then carried out a biplot that describes the distribution of the dimensions. By using a biplot, it can be explained the relationship between the variables of several analyzed variables. The biplot results for the distribution of the two dimensions are shown in Fig. 1.

As shown in the biplot results, the accident is always related to the five variables that exist as component variables regarding the vehicle. The biplot result shows that several accidents occurred due to disturbances in brake, stability, and wheel conditions. The vehicle's condition with a wheel leaning problem is followed by a brake condition that is not functioning correctly. It shows that the wheel system consisting of wheel and brake conditions will be a problem triggering accidents.

The results of this study indicate that various reasons can cause factors that influence intercity bus accidents. In general, it can be said that the factors that cause accidents cannot only be 
influenced by one factor, but several factors will trigger each other's accidents. In the case of this study, the factors of brakes, wheels, stability, and worthiness together influence or cause accidents. It's just that each variable provides a different amount of contribution depending on the condition and performance of the vehicle, which is stated in the variable coefficient in the equation. Compared with the results of previous studies as has been done by $[6,8,14]$ did not provide results on mathematical modeling, so this research resulted in differences in the form of mathematical modeling results. The PCA method is also an approach that has been used in this study and is different from the approach that has been used by previous researchers.

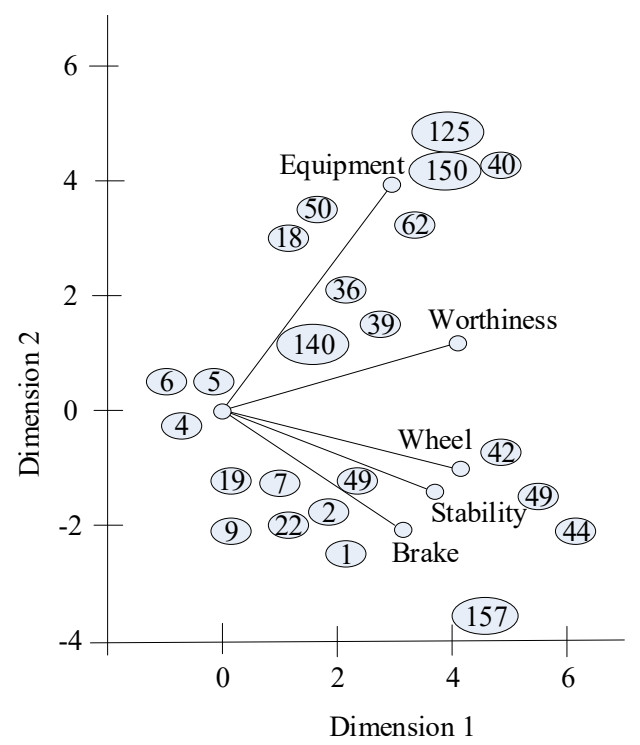

Fig. 1. Dimension biplot of the variables

This study's results certainly have unique limitations according to the objectives and characteristics of the research that has been carried out. This accident research takes secondary data from the Police.

Therefore, the data's accuracy is largely determined by the quality of the data available at the Police Office. Data reduction and compilation are also unique activities that result in processed data. This is because secondary data available at the Police Office is sometimes incomplete and inaccurate in recording accidents. However, the advantage of this research method that has been carried out is mathematical modeling results that can be used to explain the factors that cause accidents.

There is still a chance for similar research to be developed by further researchers, namely by taking accident data in one province and all countries. This is very interesting because it explains that the safety profile of intercity bus public transport is too narrow if only within the province's scope. With the scope of the whole country's territory, it will be able to explain the characteristics of a country related to the safety of public intercity bus transportation.

\section{Conclusion}

1. The five factors and four main actors, which cause intercity bus accidents, are analyzed, namely brakes, wheels, stability, and worthiness. The four factors are interrelated with each other, where these factors support each other and trigger accidents.

2. A mathematical model of the factors causing the accident are obtained, which can be explained by two mathematical equations, namely $P C_{1}=0.61 X_{1}+0.70 X_{2}+0.46 X_{3}+0.63 X_{4}+0.72 X_{5}$ and $P C_{2}=-0.47 X_{1}-0.17 X_{2}+0.76 X_{3}-0.26 X_{4}+0.31 X_{5}$.

3. Accidents caused by an inappropriate wheel are always followed by a breakdown of the braking system that is not functioning properly, and the wheel system consisting of wheel and brake conditions will be a problem triggering the accident. 


\section{Acknowledgments}

Thanks are conveyed to KNKT (National Transportation Safety Comittee) for providing support for bus public transport accident data and data related to accidents. Also, gratitude is conveyed to the agencies of the Highways Service and the East Java Transportation Service, which have contributed to the discussion regarding accidents so that they become more mature in conducting analyzes.

\section{References}

[1] Cafiso, S., Di Graziano, A., Pappalardo, G. (2012). Road Safety Issues for Bus Transport Management. Procedia - Social and Behavioral Sciences, 48, 2251-2261. doi: https://doi.org/10.1016/j.sbspro.2012.06.1198

[2] Yang, D. (2007). Trends in Transit Bus Accidents and Promising Collision Countermeasures. Journal of Public Transportation, 10 (3), 119-136. doi: https://doi.org/10.5038/2375-0901.10.3.7

[3] Lin, T.-W., Hwang, S.-L., Green, P. A. (2009). Effects of time-gap settings of adaptive cruise control (ACC) on driving performance and subjective acceptance in a bus driving simulator. Safety Science, 47 (5), 620-625. doi: https://doi.org/10.1016/ j.ssci.2008.08.004

[4] Public Transport Reform Guideline for Indonesian Cities (2019). ITDP. Available at: https://www.itdp-indonesia.org/ wp-content/uploads/2019/01/Public-Transport-Reform-Guideline-for-Indonesian-Cities-Mobilize-Revisi-1-1.pdf

[5] Suraji, A., Tjahjono, N. (2012). A Confirmatory Factor Analysis of Accidents Caused by the Motorcycle Aspect in Urban Area. International Journal for Traffic and Transport Engineering, 2 (1), 60-69.

[6] Chang, H.-L., Yeh, C.-C. (2005). Factors affecting the safety performance of bus companies - The experience of Taiwan bus deregulation. Safety Science, 43 (5-6), 323-344. doi: https://doi.org/10.1016/j.ssci.2005.07.001

[7] Suraji, A., Harnen, S., Wicaksono, A., Djakfar, L. (2017). Driver Performance Problems of Intercity Bus Public Transportation Safety in Indonesia. IOP Conference Series: Materials Science and Engineering, 267, 012026. doi: https://doi.org/10.1088/ $1757-899 x / 267 / 1 / 012026$

[8] Taylor, M. C., Baruya, A., Kennedy, J. V. (2002). The relatioship between speed and accidents on rural single-carriageway roads. Prepared for Road Safety Division, Department for Transport, Local Government and the Regions. TRL Rep. TRL 511.

[9] Smith, G. S., Huang, Y.-H., Ho, M., Chen, P. Y. (2006). The relationship between safety climate and injury rates across industries: The need to adjust for injury hazards. Accident Analysis \& Prevention, 38 (3), 556-562. doi: https://doi.org/10.1016/ j.aap.2005.11.013

[10] Sezhian, M. V., Muralidharan, C., Nambirajan, T., Deshmukh, S. G. (2011). Ranking of a Public Sector Passenger Bus Transport Company Using Principal Component Analysis: a Case Study. Management Research and Practice, 3 (1), 62-71.

[11] Ma, M., Yan, X., Huang, H., Abdel-Aty, M. (2010). Safety of Public Transportation Occupational Drivers: Risk Perception, Attitudes, and Driving Behavior. Transportation Research Record: Journal of the Transportation Research Board, 2145 (1), 72-79. doi: https://doi.org/10.3141/2145-09

[12] Porcu, F., Olivo, A., Maternini, G., Barabino, B. (2020). Evaluating bus accident risks in public transport. Transportation Research Procedia, 45, 443-450. doi: https://doi.org/10.1016/j.trpro.2020.03.037

[13] Joewono, T. B., Kubota, H. (2006). Safety and security improvement in public transportation based on public perception in developing countries. IATSS Research, 30 (1), 86-100. doi: https://doi.org/10.1016/s0386-1112(14)60159-x

[14] Hoekstra, T., Wegman, F. (2011). Improving the effectiveness of road safety campaigns: Current and new practices. IATSS Research, 34 (2), 80-86. doi: https://doi.org/10.1016/j.iatssr.2011.01.003

How to cite: Suraji, A., Djakfar, L., Wicaksono, A. (2021). Analysis of bus performance on the risk of traffic accidents in East Java-Indonesia. EUREKA: Physics and Engineering, 3, 111-118. doi: https://doi.org/10.21303/2504-5695.2021.001820 